\title{
Oxygen isotope heterogeneity among Apollo 15 green glasses
}

\author{
E.J. CANO ${ }^{1}$, Z.D. SHARP ${ }^{1}$, C.K. SHEARER ${ }^{2}$
}

${ }^{1}$ Department of Earth and Planetary Sciences, University of New Mexico, Albuquerque, NM [ejcano@unm.edu]

${ }^{2}$ Institute of Meteoritics, University of New Mexico, Albuquerque, NM

The green glass beads found within friable breccias and soils collected at the lunar surface during the Apollo 15 mission are considered one of the most primitive examples of the lunar mantle's composition. It has been established that they are likely volcanic in origin, can be subdivided into compositional groups [1], and represent the partial melting of heterogeneous olivine and orthopyroxene mantle cumulates [2]. The results from our high precision triple oxygen isotope analyses show that the very low-Ti (VLT) green glass beads from Apollo sample 15426 have $\Delta^{\prime 17} \mathrm{O}$ values that are spread between $-0.025 \%$ to $-0.066 \%$ o $(\lambda=0.528)$. This range is nearly as large as the entire variation seen throughout all lunar sample lithology. In contrast, similar measurements for the high-Ti orange/black glasses from sample 74220 produced consistent $\Delta^{\prime 17} \mathrm{O}$ values between $-0.048 \%$ and $-0.061 \%$ and have an average $\Delta^{\prime 17} \mathrm{O}$ value of $-0.056 \pm 0.004 \%$ ( $1 \sigma \mathrm{SD}$ ), similar to high-Ti basalts. The high-Ti lunar glass and MORB glass $\Delta^{\prime 17} \mathrm{O}$ measurements demonstrated much smaller standard deviations ( \pm 0.004 and $\pm 0.005 \%$ o $1 \sigma$, respectively) than those measured for the VLT green glass $( \pm 0.011 \%$ o $1 \sigma)$, confirming that the variation in the green glass is not an analytical artifact. We measured bulk samples containing mixed fractions of the VLT green glass beads and serveral fractions that were separated based on physical appearance. Both "mixed" and separated fractions exhibited a range of $\Delta^{\prime 17} \mathrm{O}$ values, however some separated fractions indicate that there may be a correlation between appearance and the $\Delta^{\prime 17} \mathrm{O}$ value. Using EPMA we identified a green glass bead that contains small anorthite fragments adhered to its surface. This shows that the heaviest $\Delta^{\prime 17} \mathrm{O}$ values measured likely represent the oxygen isotope composition of deep cumulates in the lunar mantle, and the large range of values could be the result of mixing with isotopically lighter anorthosites near the lunar surface. EPMA also identified a vitrophyric green glass bead containing a core of lattice olivine crystals. The vitrophyric glass in some beads may indicate slower rates of cooling [3], and the same bead types demonstrate the heaviest $\Delta^{\prime 17} \mathrm{O}$ values observed, suggesting a possible connection.

[1] Delano (1979) LPSC Proc. 10, 275-300. [2] Shearer et al. (1996) GCA 60, 509-528 [3] Arndt et al. (1984) J. Geophys. 89, $\mathrm{C} 225-\mathrm{C} 232$ 